\title{
Constatação do lançamento irregular de efluentes sanitários $e$ resíduos sólidos na praia Ponta D'Areia, São Luís/MA
}

Saneamento básico é um conjunto de medidas adotadas que visam modificar ou preservar as condições do meio ambiente, a inexistência desse serviço implica negativamente na qualidade de vida e saúde da população, além e provocar impactos ambientais e desequilíbrio do ecossistema. Em vista disso, é necessário criar instrumentos que devem ser aplicados para mitigar os problemas sanitários, aliados a este objetivo destaca-se a Educação Ambiental. A presente pesquisa de campo teve como objetivo fundamental constatar a existência de lançamento irregular de efluentes sanitários na praia da Ponta D'areia, localizada na cidade de São Luís/MA. Para alcance do êxito deste trabalho foram necessárias visitas à localidade no dia 18/08/2018, 20/08/2018 e 22/08/2018. No decorrer do percurso, notou-se que há presença lançamento de esgoto constante no corpo hídrico e, diante dessa realidade, é necessário que o Órgão Público tome medidas cabíveis para reverter o cenário, uma vez que o lançamento compromete a qualidade deste recurso hídrico, alterando suas características físicas, químicas e biológicas, que afetam de forma negativa à saúde da população.

Palavras-chave: Saneamento Básico; Qualidade de Vida; Efluentes Sanitários.

\section{Constatation of the irregular launch of sanitary effluents and solid waste at Ponta D'Areia beach, São Luís/MA}

Basic sanitation is a set of measures adopted to modify or preserve the conditions of the environment, the lack of this service implies negatively the quality of life and health of the population, in addition to causing environmental impacts and imbalance of the ecosystem. In view of this, it is necessary to create instruments that must be applied to mitigate the health problems, allied to this objective stands out Environmental Education. The present field research had as main objective to verify the existence of an irregular discharge of effluents in the beach of the city of São Luis/MA. To reach the goal, it was necessary to visit the locality on $18 / 08 / 2018,20 / 08 / 2018$ e 22/08/2018. During the course, it was noted that there is a simple discharge of sewage in the water body and, given this reality, it is necessary that the Public Organ take appropriate measures to reverse the scenario, since the launch compromises the quality of this water resource.

Keywords: Basic Sanitation; Quality Of Life; Effluents.

Topic: Engenharia Ambiental

Reviewed anonymously in the process of blind peer.
Received: 12/04/2020

Approved: 23/07/2020
Jeferson Botelho Rodrigues (iD)

Universidade Vale do Rio Verde, Brasil

http://lattes.cnpq.br/9702846379230129

http://orcid.org/0000-0001-6371-7912

botelhojef@gmail.com

Beatriz da Silva Alves (iD

Universidade Estadual do Maranhão, Brasil

http://lattes.cnpq.br/9471479171047300

http://orcid.org/0000-0002-9643-4625

eng.beatrizalves@gmail.com

Mariana Francisca de Sousa Moraes (iD)

Faculdade Pitágoras, Brasil

http://orcid.org/0000-0002-4380-6544

marifranciscamoraes@gmail.com
Nayara dos Santos Silva (ic

Faculdade Laboro, Brasil

http://lattes.cnpq.br/1799434246992234

http://orcid.org/0000-0002-9369-6515

nayara.sarasilva@gmail.com
Referencing this:

RODRIGUES, J. B.; ALVES, B. S.; MORAES, M. F. S.; SILVA, N. S.. Constatação do lançamento irregular de efluentes sanitários e resíduos sólidos na praia Ponta D’Areia, São Luís/MA. Engineering Sciences, v.8, n.2, p.68-74, 2020. DOI: http://doi.org/10.6008/CBPC2318-3055.2020.002.0007 


\section{INTRODUÇÃO}

Entre os variados ambientes costeiros existentes, as praias destacam-se por executar um importante papel para o equilíbrio ecológico, por abrigar diversas espécies de seres vivos, e por propiciar serviços ao homem, como ajuste da manutenção do clima, controle de inundações e proteção à zona costeira (SODRE et al., 2010).

De acordo com Derísio (2000), a água é um elemento fundamental para a sobrevivência da humanidade e por isso se torna um dos recursos naturais indispensáveis à manutenção da vida. A água é utilizada em diversas áreas, tais como abastecimento industrial e doméstico, dessedentação de animais, irrigação de produtos orgânicos, preservação da flora e fauna, lazer e recreação, geração e desenvolvimento da energia elétrica, diluição de despejos e navegação. A proteção da qualidade da água é um dos principais aspectos da gestão ambiental e, por conseguinte, evitar a poluição deste bem natural é de crucial importância.

O Ministério do Meio Ambiente ao estabelecer o 'meio ambiente ecologicamente equilibrado' como direito dos brasileiros, 'bem de uso comum e essencial à sadia qualidade de vida', também, atribui ao 'Poder Público e à coletividade o dever de defendê-lo e preservá-lo para as presentes e futuras gerações'. Neste sentido, trata-se da defesa e preservação pelo Poder Público e pela coletividade, de um bem público (o meio ambiente ecologicamente equilibrado), cujo modo de apropriação dos seus elementos constituintes, pela sociedade, pode alterar as suas propriedades e provocar danos ou, ainda, produzir riscos que ameacem a sua integridade.

A mesma coletividade que deve ter assegurado o seu direito de viver num ambiente que the proporcione uma sadia qualidade de vida, também precisa utilizar os recursos ambientais para satisfazer suas necessidades. Na vida prática, o processo de apropriação e uso dos recursos ambientais não acontece de forma tranquila. Há interesses em jogo e conflitos (potenciais e explícitos) entre atores sociais que atuam de alguma forma sobre os meios físico-natural e construído, visando o seu controle ou a sua defesa (SOUZA, 2009).

De acordo com Von Sperling (2005) refere-se à poluição das águas como ocasionada pela adição de substâncias ou de formas de energia que, direta ou indiretamente, alterem a natureza do corpo d'água de uma maneira tal que prejudique os legítimos usos que dele são feitos. As fontes de poluição das águas superficiais são os esgotos domésticos e industriais, as águas pluviais que transportam impurezas da superfície do solo ou que contêm esgotos lançados nas galerias que coletam as águas da chuva, resíduos sólidos, pesticidas, fertilizantes e detergentes.

Machado et al. (2003) afirma ser de suma importância o conhecimento prévio dos possíveis danos acarretados ao meio ambiente, advindos do lançamento de cargas poluidoras, para que seja garantido o uso futuro dos recursos hídricos, bem como a preservação ambiental. O presente trabalho tem como objetivo principal constatar a existência de lançamento de esgoto de efluentes não tratados e despejos de resíduos sólidos na orla marítima de São Luís, especificamente na Praia Ponta D’Areia. 


\section{MATERIAIS E MÉTODOS}

Com uma população de 1094667 habitantes, São Luís é o município mais populoso do Maranhão, além de ser o $15^{\circ}$ município mais populoso do Brasil, e o $4^{\circ}$ da Região Nordeste. Sua área é de $831,7 \mathrm{~km}^{2}$, desse total $283 \mathrm{~km}^{2}$ estão em perímetro urbano. O clima de São Luís é tropical, quente e úmido. A temperatura mínima na maior parte do ano é de 22 a 24 graus e a máxima varia entre 30 e 34 graus (IBGE, 2016).

A metodologia do trabalho se deu através pesquisa de campo de caráter exploratório e observatório intensiva, com visitas à Praia Ponta D'areia nos dias 18/08, 20/08 e 22/08 do ano de 2018. No dia 18/08 foi possível conhecer e analisar a extensão e usos da praia em questão. Na data de 20 e 22/08 foi realizada caminhada ao longo da zona costeira estudada em busca de reconhecer pontos específicos que pudessem estar contribuindo com impactos ambientais negativos. Nas visitas foi constatado forte odor oriundo de despejo de efluentes líquidos de origem sanitária em somente um ponto da praia ponta d’areia.

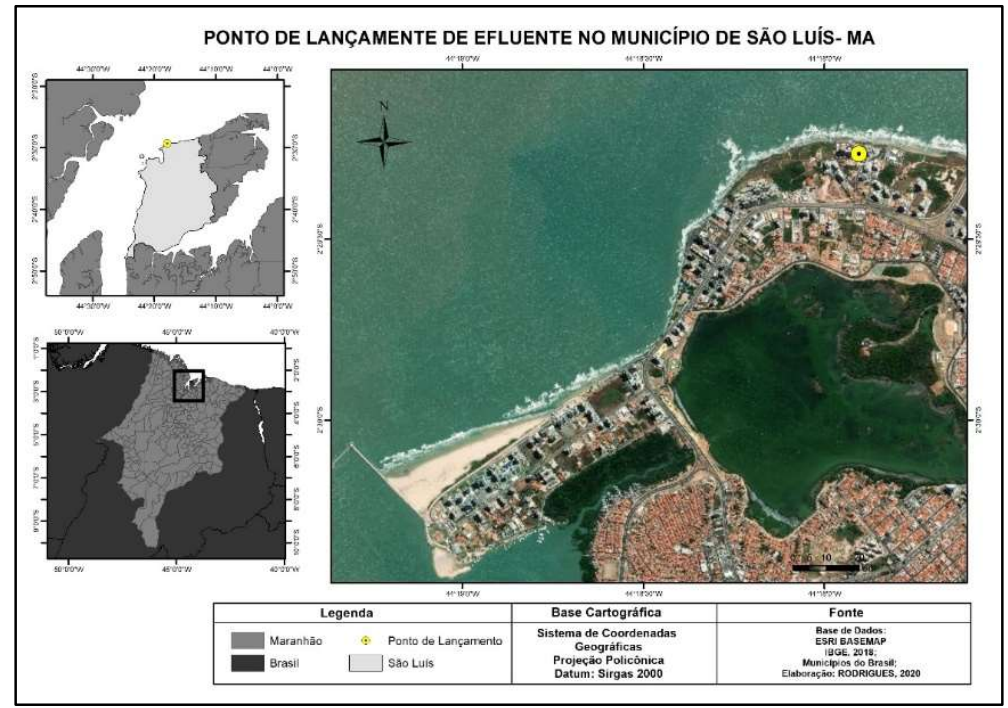

Figura 1: Mapa de localização da área estudada.

\section{RESULTADOS E DISCUSSÃO}

No decorrer do percurso na orla marítima, notou-se a presença de lançamento irregular de efluentes não tratados no mar. O lançamento de efluentes em corpos hídricos gera impactos no solo, contaminação dos recursos hídricos, desequilíbrio no ecossistema marinho, comprometendo assim a qualidade da água. Segundo Barros (1995), os reflexos nefastos dessas transformações fizeram-se presentes no meio ambiente, principalmente nos núcleos urbanos, onde a poluição e suas formas contaminantes se tornaram mais evidentes. Indubitavelmente, a poluição atingiu direta e em maior intensidade, os recursos hídricos, seguidos pelo ar atmosférico e ultimados pelos solos; sem entrarmos em considerações quanto aos impactos ao meio biótico - florístico e faunístico.

De acordo com a Agência Nacional de Águas - ANA (2017), a deficiência na coleta e tratamento de esgotos nos municípios brasileiros tem gerado uma fração expressiva na abundancia de poluição que chega aos corpos hídricos, isso afeta negativamente a qualidade da água comprometendo seus usos múltiplos. 
Prosseguindo com dados de coleta e tratamento de esgoto, a agência relata que no Brasil, 43,45\% da população dispõem do esgoto coletado e tratado, sendo que $12.03 \%$ utilizam da solução individual (fossa séptica), isso quer dizer que $55 \%$ da população usufruem de uma forma de tratamento considerada adequada; $18,2 \%$ possuem a coleta de esgoto, mas o mesmo não é tratado, o que pode ser considerado como atendimento precário; e $26,33 \%$ não possuem coleta e nem tratamento, isto é, sem atendimento por serviço de coleta sanitário, como apresentado na figura 2.

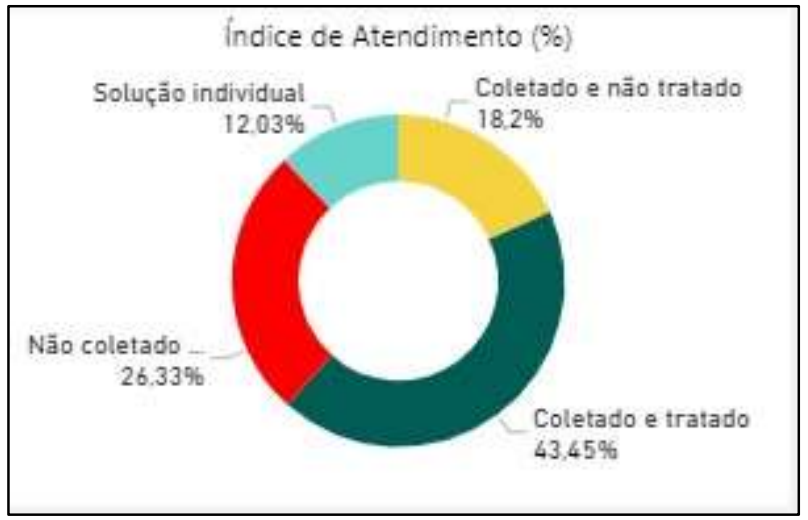

Figura 2: Índice de atendimento de coleta e tratamento de esgoto no Brasil. Fonte: ANA (2013).

No Maranhão 3,92\% do esgoto é coletado e tratado, sendo que $13 \%$ é coletado e não é tratado; $22,22 \%$ da população utilizam a solução individual; e 60,86\% do esgoto não é coletado e nem tratado, como mostrado na figura 3.

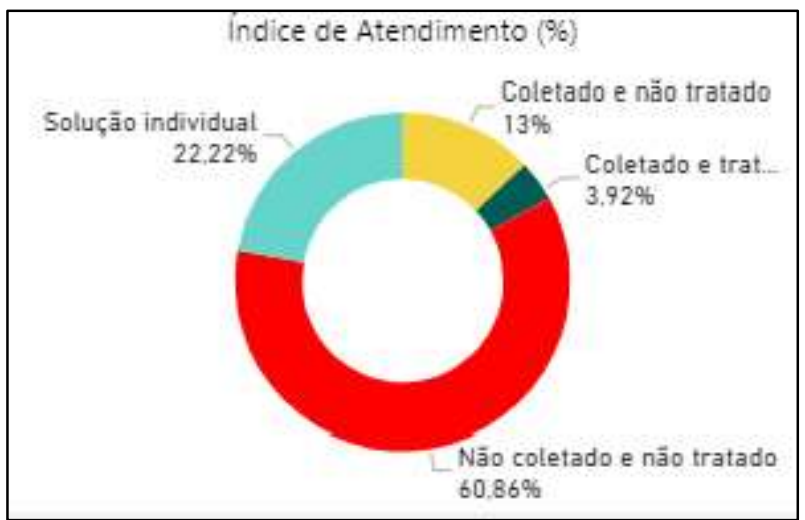

Figura 3: Índice de atendimento de coleta e tratamento de esgoto no Maranhão. Fonte: ANA (2013).

No município de São Luís/MA apenas 3,78\% da população usufruem coleta e tratamento de esgoto, enquanto 44,31\% possuem seu esgoto coletado, porém não é tratado; $19,42 \%$ tem atendimento por solução individual; e 32,48\% não dispõe de coleta e nem tratamento de esgoto, conforme a figura 4.

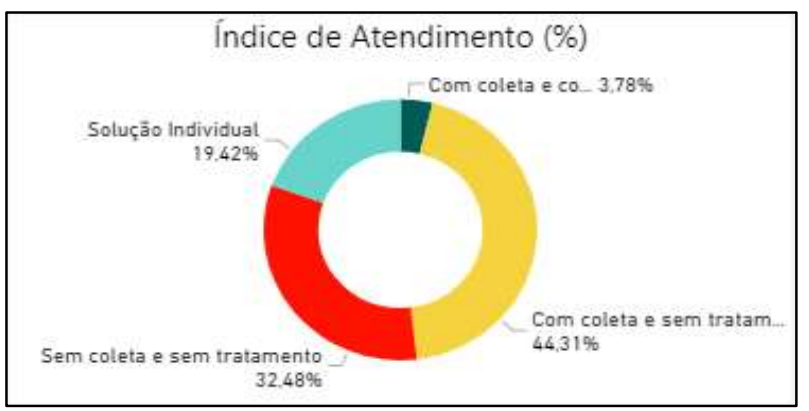

Figura 4: Índice de atendimento de coleta e tratamento de esgoto em São Luís - Maranhão. Fonte: ANA (2013). 
Através das imagens 5 e 6, é possível notar a presença e lançamento de esgoto irregular que há nos recursos hídricos, assim podendo causar diversos impactos nos recursos naturais que estão em volta. Uma vez que estes recursos sejam poluídos e/ou contaminados, a qualidade da praia irá se tornar imprópria para qualquer atividade de lazer. Acredita-se que este lançamento seja proveniente das residências que estão em torno da orla.

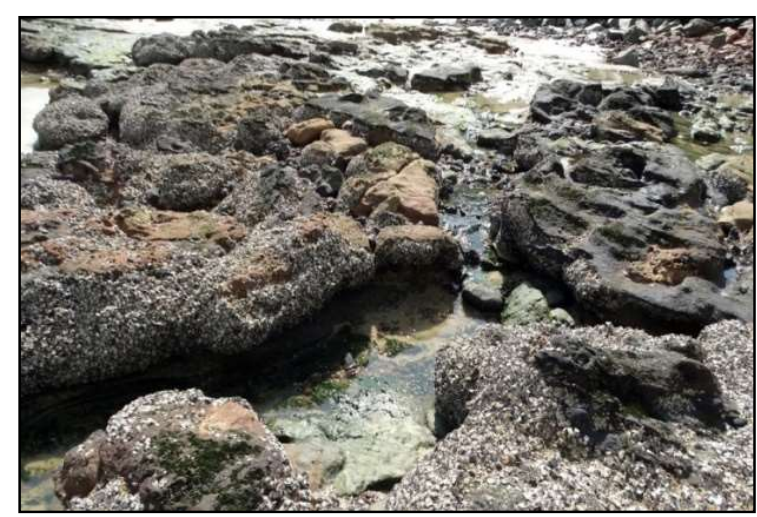

Figura 5: Lançamento irregular de efluente em um ponto na praia ponta d'areia, São Luís.

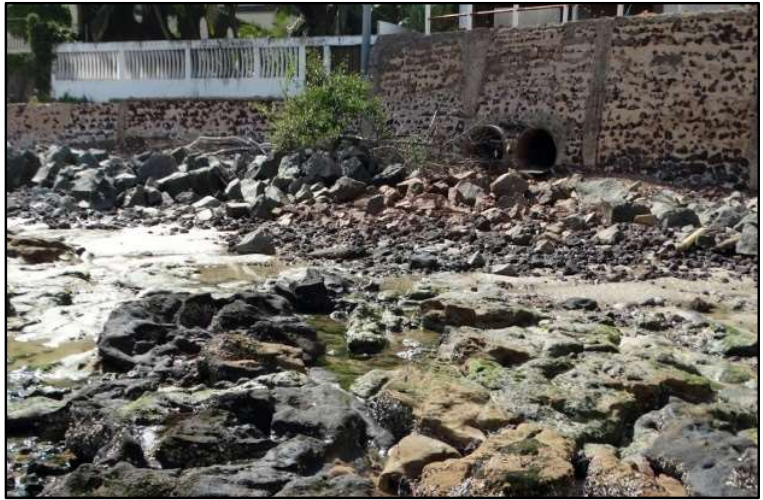

Figura 6: Lançamento irregular de efluente em um ponto na praia ponta d'areia, São Luís/MA.

Nas imagens 7 e 8 é possível notar além do lançamento irregular de esgoto, a presença de resíduos sólidos com destinação final de forma incorreta, comprometendo não só a qualidade ambiental como também, a comunidade biológica e a saúde pública. Segundo Cheshire et al. (2009) os lixos em ambientes marinhos podem causar impactos sociais por meio da poluição visual, ocasionando inevitavelmente perdas dos valores estéticos e/ou visuais, além de riscos à saúde e segurança pública; e também impactos econômicos com a perda do valor turístico regional, danos a pesca e aquicultura, e a geração de custos com programas de limpeza da praia.

Os resíduos sólidos presentes em ambientes marinhos estão diretamente relacionados às ações antrópicas adversas que afetam não apenas as praias próximas, mas também as mais distantes, como é o caso do lixo flutuante que pode ser conduzido através das correntes marinhas (BRAVO et al., 2009). Os mesmos em geral são compostos de material pouco degradável ou não degradável que se acumula no ambiente, ocasionando assim grandes perturbações (UNEP/GPA).

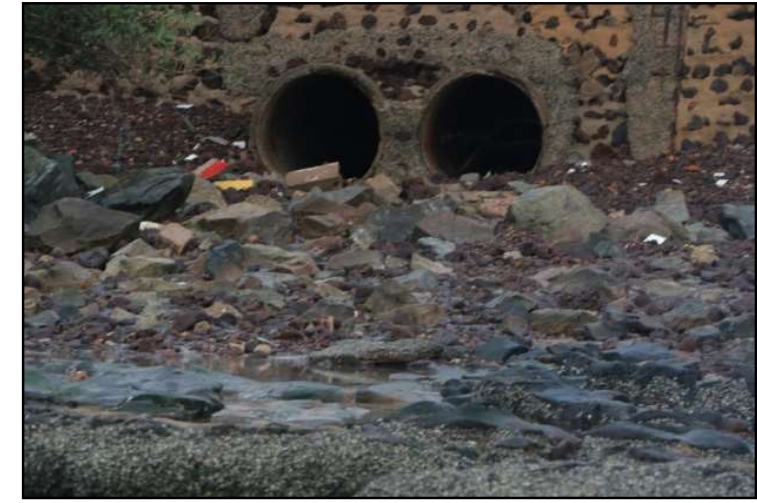

Figura 7: Lançamento irregular de efluente e resíduos sólidos em um ponto na praia ponta d'areia, São Luís/MA.

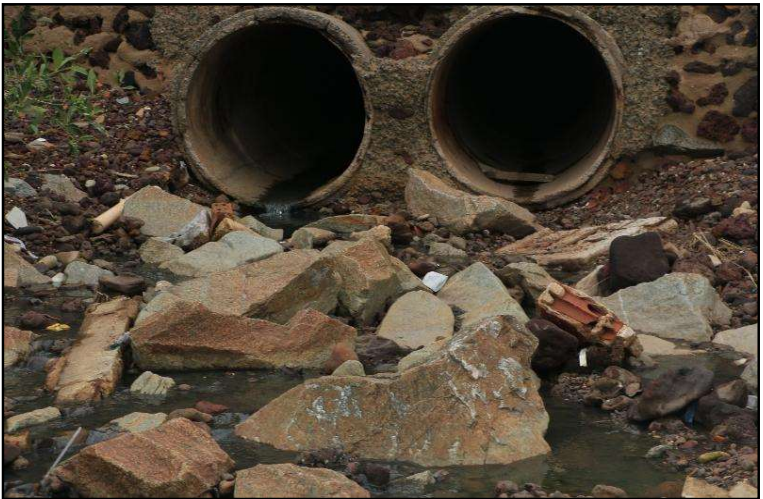

Figura 8: Lançamento irregular de efluente e resíduos sólidos em um ponto na praia ponta d'areia, São Luís/MA. 
Dentre as várias tecnologias disponíveis para o tratamento de águas residuárias em ambientes costeiros, a utilização de emissários submarinos como parte integrante do sistema de tratamento aparece como uma alternativa sustentável para melhorar a qualidade da água (ECHAVARRI-ERASUN et al., 2010; JUANES et al., 2005), além de reduzir substancialmente os custos de investimentos, operação e manutenção enquanto alcançam os mesmos objetivos de qualidade ambiental de tratamentos com elevados níveis sem uma otimização do lançamento (ROBERTS et al., 2010). Com isso, pode-se dizer que se assevera a necessidade do tratamento e destinação correta de efluentes, pois devido a sua grande expansão, o lançamento incorreto dos efluentes contaminará a área, assim tornando a população mais vulnerável às doenças causadas por veiculação hídrica.

\section{CONCLUSÕES}

Durante todo o percurso realizado, foi possível observar que há presença de lançamento irregular de efluentes diretamente no mar. Por conseguinte, é de extrema e urgência necessidade que o Poder Público deve tomar medidas urgentes a respeito desse atual cenário, pois os recursos hídricos estão sendo comprometidos e, consequentemente a população está vulnerável a esse deplorável cenário. Aliado a isto é necessário que seja trabalhada a educação ambiental da população sobre os cuidados com o meio ambiente e, sobretudo os recursos hídricos a fim de conscientizá-los e sensibilizá-los como uma forma de alerta aos danos sociais, econômicos e ambientais associados ao meio ambiente, ao ecossistema e a saúde pública.

\section{REFERÊNCIAS}

ANA. Agência Nacional de Águas. Atlas esgotos: despoluição de bacias hidrográficas. Brasília: ANA, 2017.

ANA. Agência Nacional de Águas. Tabela completa dos municípios. Brasília: ANA, 2013.

BARROS, R. T. V.. Manual de Saneamento e Proteção Ambiental para os Municípios. Belo Horizonte: Escola de Engenharia da UFMG, 1995.

BRAVO, M.; GALLARDO, M. Á.; LUNA-JORQUERA, G.; NÚÑES P.; VÁSQUEZ, N.; THIEL, M.. Anthropogenic debris on beaches in the SE Pacific (Chile): Results from 50 a national survey supported by volunteers. Marine Pollution Bulletin, v.58, n.11, p.1718-26, 2009.

CHESHIRE, A. C.; ADLER, E.; BARBIÈRE, J.; COHEN, Y.; EVANS, S.; JARAYABHAND, S.; JEFTIC, L.; JUNG, R. T.; KINSEY, S.; KUSUI, E. T.; LAVINE, I.; MANYARA, P.; OOSTERBAAN, L.; PEREIRA, M .A.; SHEAVLY, S.; TKALIN, A.; VARADARAJAN, S.; WENNEKER, B.; WESTPHALEN, G.. UNEP/IOC Guidelines on Survey and Monitoring of Marine Litter. UNEP Regional Seas Reports and Studies, v.186, n.83, p.120, 2009.

DERÍSIO, J. C.. Introdução ao controle de poluição ambiental. São Paulo: Signus, 2000.

ECHAVARRI-ERASUN, B.; JUANES, J. A.; PUENTE, A. REVILLA, J. A.. Coastal outfalls, a sustainable alternative for improving water quality in north-east Atlantic estuaries. Journal of
Environmental Monitoring, v.12, p.1737-1746, 2010. DOI: http://dx.doi.org/10.1039/B927243G

JUANES, J. A.; REVILLA, J. A.; ÁLVAREZ, C.; GARCÍA, A.; PUENTE, A.; NIKOLOV, K.. Environmental design and monitoring of large submarine outfalls: an integrated approach for coastal protection. In: ZIMMERMANN, C.; DEAN, R. G.; PENCHEV, V.; VERHAGEN, H. J..

Environmentally friendly coastal protection. Dordrecht: Springer, 2005. p.243-253.

MACHADO, E.; PORTO, M.; RAMON, N.; FEIL, A.. Um Avanço na Gestão da Qualidade de Água: A outorga de lançamento de efluentes. In: SIMPÓSIO BRASILEIRO DE RECURSOS HÍDRICOS, 15. Anais. 2003.

ROBERTS, P. J. W.; SALAS, J. H.; REIFF, F. M.; LIBHABER, M.; LABBE, A.; THOMSON, J. C.. Marine wastewater outfalls and treatment systems. London: IWA Publishing, 2010.

SODRE, E. S. P.; FARIAS FILHO, M. S.. Perda de qualidade ambiental nas praias de São Marcos e Calhau em São Luís do maranhão em função da poluição por resíduos sólidos e deposição de efluentes líquidos. In: ENCONTRO NACIONAL DE GEÓGRAFOS, 16. Anais. 2010.

SOUZA, J. B. C.. Percepção Ambiental na Praia de Boa Viagem, São José de Ribamar, Maranhão. In: SIMPÓSIO BRASILEIRO DE GEOGRAFIA FÍSICA APLICADA, 13. Anais. Viçosa, 2009. 
VON SPERLING, M.. Princípios do tratamento biológico de águas residuárias. In: Introdução à qualidade das águas e ao tratamento de esgotos. Belo Horizonte: Departamento de Engenharia Sanitária e Ambiental - UFMG, 1995.

A CBPC - Companhia Brasileira de Produção Científica (CNPJ: 11.221.422/0001-03) detém os direitos materiais desta publicação. Os direitos referem-se à publicação do trabalho em qualquer parte do mundo, incluindo os direitos às renovações, expansões e disseminações da contribuição, bem como outros direitos subsidiários. Todos os trabalhos publicados eletronicamente poderão posteriormente ser publicados em coletâneas impressas sob coordenação da Sustenere Publishing, da Companhia Brasileira de Produção Científica e seus parceiros autorizados. Os (as) autores (as) preservam os direitos autorais, mas não têm permissão para a publicação da contribuição em outro meio, impresso ou digital, em português ou em tradução. 